\title{
Structural Characterization of Membrane-Electrode-Assemblies in High Temperature Polymer Electrolyte Membrane Fuel Cells
}

Bodner, Merit ; Bentzen, Janet Jonna; Dahl, Vedrana Andersen; Alfaro, Silvia M.; Steenberg, Thomas ; Hjuler, Hans Aage ; Simonsen, Søren Bredmose

Published in:

Journal of The Electrochemical Society

Link to article, DOI:

$10.1149 / 2.0981914$ jes

Publication date:

2019

Document Version

Peer reviewed version

Link back to DTU Orbit

Citation (APA):

Bodner, M., Bentzen, J. J., Dahl, V. A., Alfaro, S. M., Steenberg, T., Hjuler, H. A., \& Simonsen, S. B. (2019). Structural Characterization of Membrane-Electrode-Assemblies in High Temperature Polymer Electrolyte Membrane Fuel Cells. Journal of The Electrochemical Society, 166(14), F1105-F1111.

https://doi.org/10.1149/2.0981914jes

\section{General rights}

Copyright and moral rights for the publications made accessible in the public portal are retained by the authors and/or other copyright owners and it is a condition of accessing publications that users recognise and abide by the legal requirements associated with these rights.

- Users may download and print one copy of any publication from the public portal for the purpose of private study or research.

- You may not further distribute the material or use it for any profit-making activity or commercial gain

- You may freely distribute the URL identifying the publication in the public portal 


\section{Evaluation of methods for characterisation of membrane-electrode- assemblies in high temperature polymer electrolyte membrane fuel cells}

Merit Bodner ${ }^{1}$, Janet Jonna Bentzen ${ }^{2}$, Vedrana Andersen Dahl ${ }^{3}$, Silvia M. Alfaro ${ }^{1}$, Thomas Steenberg ${ }^{1}$, Hans Aage Hjuler ${ }^{1}$, and Søren Bredmose Simonsen ${ }^{2, *}$

${ }^{1}$ Danish Power Systems, Egeskovvej 6C, 3490 Kvistgaard, Denmark

2 Department of Energy Storage and Conversion, Technical University of Denmark, Frederiksborgvej 399, 4000 Roskilde, Denmark

${ }^{3}$ Department of Applied Mathematics and Computer Science, Technical University of Denmark, Richard Petersens Plads, 2800 Kgs. Lyngby, Denmark

[*]Corresponding author: sobrs@dtu.dk

\section{Abstract}

Polybenzimidazole membranes doped in phosphoric acid are used as electrolyte in high temperature polymer electrolyte fuel cells. Electrolyte membranes are crucial to assure high performance. Profound understanding of changes in the membrane thickness, which directly relate to the amount of absorbed acid, is thus needed for optimization of fuel cells. In this study, scanning electron microscopy and X-ray micro-computed tomography are compared regarding their reliability and suitability for determining the thickness of said membranes. Semi-automated layer identification and thickness estimation was used to reduce human errors and data processing time. The results show that scanning electron microscopy is suitable for investigating the membrane thickness of selected cross sections, while the non-destructive X-ray computed tomography offers more 3D details of the same membrane at different stages, e.g. before and after cell test. Specifically, hot pressing, crucial in the manufacturing of membrane-electrode-assemblies, was identified as the step in which the membrane loses $52 \%$ of its thickness. This is expected to occur due to acid being pressed from the membrane into the gas diffusion electrodes and eventually being removed with the gas flow. After operation, further compression of the membrane was observed in a pattern identical to that of the flow plate channels. 
Keywords: Electrolyte thickness; Electron microscopy; Fuel cells; High temperature polymer electrolyte membrane fuel cell; Phosphoric acid loss; Scanning electron microscopy; X-ray micro-CT

\section{Introduction}

Within the last century, the reliance on fossil fuels has led to tremendous emission of $\mathrm{CO}_{2}$ to the atmosphere. The effect thereof on the environment is undeniable and needs to be addressed with utmost urgency. This requires a fundamental change in the energy supply and distribution chain, by relying on the implementation of carbon-free, sustainable technologies. Various options have been developed in the past, yet few possess the potential for market penetration, as the need to compete economically and practically with the relatively low-priced fossil fuels and their existing and welldeveloped infrastructure. Fuel cells are among the few technologies that are able to fulfil these requirements. They most commonly rely on hydrogen or hydrogen rich reformate gas, which can be generated from a variety of feedstocks - fossil or renewable - and thus allow a smooth transition. Furthermore, fuel cell production costs and raw material demands are constantly declining, giving fuel cells the perspective to become economically viable in the near future $[1,2]$.

High temperature polymer electrolyte membrane fuel cells (HT-PEMFCs) stick out among the other types of fuel cells, as they combine a high resilience towards common gas impurities - avoiding the necessity for extensive purification with an easy water management and an efficient thermal integration due to their elevated operation temperatures in comparison with low temperature PEMFCs. Still, they are also characterised by fast start up and low material demands due to the relatively low temperature compared to e.g. solid oxide fuel cells. HT-PEMFC technology is in the process of emerging to the market and a number of commercial products are available $[3,4]$. 
However, there is still room for improvement in durability, performance and catalyst utilization of fuel cells. Development activities in this field demand proper tools for identifying and understanding various lifetime limiting mechanisms, as these are complex and highly interrelated. Different characterisation methods can be applied to determine structure and time-depended structural changes of membrane and electrodes as well as their interface, but all approaches possess unique characteristics and therefore limitations. In order to be able to generate usable results, a broad understanding of the respective techniques is required [5].

One commonly used tool is electron microscopy $[6,7]$. This usually requires exposure of the samples to vacuum, which can be expected to have an impact on certain materials. Among these is the membrane of the HT-PEMFC, which most commonly consists of phosphoric acid (PA) doped polybenzimidazole (PBI). $\mathrm{PBI}$ is in dry as well as in doped state prone to taking up to $19 \%$ water up if exposed to humidity [8]. Furthermore, PA has a low but existing vapour pressure and thus might evaporate or dehydrate, forming pyrophosphate, when doped membranes are exposed to vacuum [9]. In addition, destructive sample preparation methods, such as cutting the membrane-electrodeassembly (MEA), are necessary. Both evaporation and sample preparation can potentially alter the appearance of the membranes in SEM images significantly and this thus requires investigation.

In contrast, the inner parts of fuel cells can be studied by using X-rays in an ambient atmosphere and without destructive sample preparation. In addition, X-ray computed tomography (CT) offers detailed information of the inner structure in 3D. The methods have recently been used to conduct in situ characterisation following dynamical changes in low and high temperature PEMFCs $[10,11]$. However, compared to electron microscopy, X-ray CT suffers from lower special resolution and lower signal-tonoise ratio. For this reasons, extracting quantitative information from X-ray CT images can be challenging, and it is important to validate the quantifications across modalities.

In this study, we compare advantages and limitations of scanning electron microscopy (SEM) with Xray micro-computed tomography $(\mu \mathrm{CT})$ for the characterisation of high temperature PEM fuel cells. 
Specifically, we focus on the characterisation of the thickness of the fuel cell electrolyte by comparing SEM imaging with two different $\mathrm{X}$-ray $\mu \mathrm{CT}$ imaging settings.

\section{Experimental}

\subsection{Sample Preparation}

All materials investigated in this study were produced by Danish Power Systems, Kvistgaard, Denmark. PA doped PBI electrolyte membranes were assembled to membrane-electrode-assemblies (MEAs) with gas diffusion electrodes (GDE) containing PtCo/C made in the set-up phase of the production process [12]. The doping method is described in [13]. The symmetric catalyst-electrolyte-catalyst core is sandwiched between micro porous layers (MPL) and a carbon fibre gas diffusion layers (GDL) on both sides. The active surface area of each MEA is $21 \mathrm{~cm}^{2}$ and has quadratic dimensions. The MEAs were hot-pressed at $100{ }^{\circ} \mathrm{C}$ and a pressure of $2.3 \mathrm{MPa}$ for 3 minutes with hard stops, preventing over compression of the GDLs. In addition, one set of materials was not compressed to investigate the impact of the MEA assembly procedure on the electrolyte thickness. In this case, membrane and GDEs were simply stacked as for assembly but not processed further before scanning.

\subsection{Electrochemical Testing}

For cell testing, MEAs were placed in a single cell setup and operated steadily at $0.4 \mathrm{~A} \mathrm{~cm}^{-2}$ for $65 \mathrm{~h}$ at $160^{\circ} \mathrm{C}$, with air and wet reformate on cathode and anode, respectively. During this time, an initial loss of phosphoric acid from the membrane due to the compression is expected to take place and the membrane water uptake has time to equilibrate. The composition of the reformate fuel was chosen to mimic that of the product gas of a methanol reformer.

\section{3. $\underline{\mathrm{X}-\operatorname{ray} \mu \mathrm{CT}}$}

X-ray $\mu \mathrm{CT}$ scans were conducted using two different scanners: For high resolution, a lab-based Xradia Versa XRM-410 instrument using a W reflection target and a CCD with $2000 \times 2000$ pixels was used. Scans were performed at a voltage of $60 \mathrm{kV}$, a power of $10 \mathrm{~W}$, no filter, $4 \times$ optical magnification, 
binning 1 , an exposure time of $15 \mathrm{~s}$ and a total of 3201 projections over a $360^{\circ}$ rotation, resulting in a pixel resolution of $1.9 \mu \mathrm{m}$ and a field of view of $3.6 \mathrm{~mm} \times 3.6 \mathrm{~mm}$. For large field of view, we used a lab-based Nikon XT H225 instrument with a W reflection target and a Perkin Elmer 1620 detector with $2000 \times 2000$ pixels. The scans were performed using a voltage of $60 \mathrm{kV}$, a power of $8 \mathrm{~W}$, no filter, binning of 1, an exposure time of $4 \mathrm{~s}, 4$ frames per projection and a total of 3142 projections over a $360^{\circ}$ rotation, resulting in a pixel resolution of $6.6 \mu \mathrm{m}$ and a field of view of $11 \mathrm{~mm} \times 11 \mathrm{~mm}$.

For all scans the entire MEAs were placed vertically in an almost X-ray transparent foam with the purpose of holding and stabilizing the MEA (Figure 1). The MEAs were not folded, and no destructive sample preparation, such as cutting, was applied. Only the excess membrane on the sides was carefully folded to enable a minimum distance between sample centre and X-ray source without harming the structural integrity (See Figure 1). The MEAs were kept in sealed plastic bags during scanning and storage. After electrochemical testing, the MEAs were mounted identically to the initial scan and scanned again.

The recorded data was reconstructed using Feldkamp-Davis-Kress reconstruction algorithm with no beam hardening corrections.

\subsection{Electron Microscopy}

MEA cross sections were obtained in the proximity of the centre of field of view of the X-ray $\mu \mathrm{CT}$. Cuts were made by a sharp knife without further treatment such as metal coating or resin casting. A Zeiss EVO MA10 was used in back scatter mode for the SEM imaging.

Images of the non-compressed sample for comparison could not be obtained with this method due to the lack of mechanical integrity of the membrane outside of an MEA.

\subsection{Data Analysis}

The electrolyte thickness was manually measured from an SEM image and from a slice in the 3D datasets by using the software ImageJ. This was done by dragging a line over the membrane at 20 
different locations. The mean membrane thickness was calculated from the 20 values, the standard deviation of the mean (SDOM) is used as an estimated error for the mean thickness, and the standard deviation (SD) was used as an indicator of the thickness variation.

For the large field of view X-ray CT dataset where the limited spatial resolution generally resulted in poorly defined interfaces, a specially developed algorithm based on layered surface detection [14] was in addition used to find the interfaces between the electrolyte and electrodes. The algorithm utilizes the fact that the imaged electrolyte layer appears grey, while catalyst layers $(\mathrm{CL})$ contain brighter and darker areas corresponding to Pt and the pores. For this reason, the algorithm will obtain precise measurements only in areas where electrolyte membrane is sandwiched between catalyst layers.

For the first step of the algorithm, the user sets two grey values that reflect the intensity limits of the electrolyte $(\mathrm{PBI}+\mathrm{PA})$. Using the fuzzy (soft) thresholding, the pixels with intensity within these limits are assigned a high probability of being electrolyte. The pixels with intensities outside these limits are assigned a low probability of being in electrolyte. This includes pixels with high intensity (containing Pt) and pixels with low intensity (carbon and pores).

The second step of the algorithm detects four terrain-like surfaces in the volume according to the geometric constraints and the optimality criterion [14]. The geometric constraints limit the roughness of the surfaces and set the limits for the distances between the surfaces. The optimality criterion, guided by the outcome of the first step of the algorithm, assures that the layer between the second and the third surface has an overall high probability of being an electrolyte, while the opposite is valid for the layers above and below.

Fine-tuning of the surface detection is done by the user by changing one parameter at a time until the best match of the detected surfaces to the data is determined through visual inspection. The process is iterated since each parameter interdependently influences the final result. In this study, we focus 
entirely on the electrolyte membrane thickness, and therefore the surface detection was only optimised for parameters influencing the thickness of the layer identified as electrolyte.

The intensity thresholds for electrolyte were estimated to 40 and 135, with fuzziness parameter set to 50 and the surfaces were not allowed to cross each other, but defined to have a minimum thickness of 1 pixel. The same threshold values were used for all three analysed datasets in order to limit any subjective bias.

After layer detection, the mean electrolyte thickness was calculated by averaging the values over the entire imaged area of the MEA. Also, thickness distribution histograms and maps as well as centre line images were extracted from the 3D datasets. Since the SDOM value decreases with the number of measurement points and the large field of view dataset contains several thousands of these, the SDOM cannot here be used as a reliable estimate for the measurement error. Instead, the layer finding algorithm was applied two times more, where the intensity thresholds were increased/decreased until the determined electrolyte layer was clearly too thick (reaching into the catalyst layers) or too thin (catalyst layers reach into the electrolyte). The estimated error on the measured electrolyte membrane thickness was calculated as the absolute value of the difference between these additional thicknesses and the thickness obtained when the layer finding algorithm was optimized as described above.

\section{Results and Discussion}

\subsection{Comparison of Imaging Methods}

Figure 2 presents (a) a backscattered SEM and $(b, c)$ two X-ray CT images, all taken in a similar region of the same MEA after cell test. The X-ray CT images are all slices from 3D datasets reconstructed from (b) high resolution and (c) large field of view X-ray $\mu \mathrm{CT}$ scans. The images show all the active layers of the MEA, including the GDL, MPL, catalyst layer and, in the centre, the electrolyte membrane. In all images, the contrast reflects variations in density, because scattering of both electrons and X-rays increases with the concentration and atomic number of elements in the sample. With this information, 
the electrolyte membrane $(\mathrm{PA}+\mathrm{PBI})$ is identified as the central layer between the brighter, platinum containing catalyst layers.

The SEM image shows delamination between the top MPL and catalyst layer (Figure 2a). The delamination occurred during SEM sample preparation and is therefore not observed in the X-ray CT images. This illustrates one of the main disadvantages of SEM analysis of these soft materials, i.e. the morphologies observed with SEM can easily have been modified during sample preparation. On the other hand, the finer details are better presented by the SEM image due to its nanoscale resolution, while only microscale features are resolved in the X-ray CT images.

In this study, we focus primarily on the thickness of the electrolyte membrane. The mean membrane thickness was measured manually to be $43 \mu \mathrm{m}$, standard deviation (SD) $=5 \mu \mathrm{m}$ and standard deviation of the mean $(\mathrm{SDOM})=1 \mu \mathrm{m}$ according to $\mathrm{SEM}$, to $41 \mu \mathrm{m}, \mathrm{SD}=6 \mu \mathrm{m}, \mathrm{SDOM}=1 \mu \mathrm{m}$ according to high resolution X-ray $\mathrm{CT}$ and to $42 \mu \mathrm{m}, \mathrm{SD}=10 \mu \mathrm{m}, \mathrm{SDOM}=2 \mu \mathrm{m}$ according to large field of view X-ray CT. The thicknesses measured by SEM and X-ray CT are therefore almost identical when taking the estimated measurement error (i.e. SDOM) into account.

It could have been expected that the vacuum required for obtaining SEM images could result in a decreased membrane thickness due to evaporation of water or even PA. It could also have been expected that the membrane thickness near the SEM images surface had decreased by the pressure from the knife during cutting. Interestingly, according to Figure 2, sample preparation and exposure to vacuum did not result in a detectible change in the electrolyte membrane thickness from SEM images. The results suggest that although the $\mathrm{X}$-ray $\mathrm{CT}$ data offer a more realistic representation of the non-disturbed cell; SEM imaging nevertheless offers reliable membrane thickness evaluations.

Obviously, there are more information in 3D data than presented by single 2D images. To illustrate this, Figure 3a presents three orthogonal slices. The horizontal slice cuts through the lower $\mathrm{CL}$ and clearly shows the structure of the layer to an extent that is not possible in $2 \mathrm{D}$ images as those shown in Figure 2. A better view of the 3D structure of selected layers in the MEA is given in Figure 3b. Here 
it is evident that the fibre orientation in the GDL layers is not random, but that the main part of the fibres is oriented in the almost same direction (Figure $3 \mathrm{~b}$ ). Algorithms are available to extract detailed information about the directions of fibres from at 3D dataset [15]. Recent studies using X-ray or FIBSEM tomography have shown other examples of information that can only be obtained from a 3D dataset, for example tortuosity, connectivity and triple phase boundaries [16-20]. This, however, is beyond the scope of the present study.

\subsection{Large Field of View Thickness Analysis}

In the present study, we are interested in assessing the electrolyte membrane thickness and, if any, its changes during handling and cell testing. The main advantage of X-ray CT compared to SEM is therefore that it is non-destructive, which makes it possible to scan the same MEA before and after cell test. To make sure that the analysed area of MEA is representative, the scan should cover as large a part of the MEA as possible and thus a large field of view X-ray CT scan was chosen.

However, in the images from the large field of view scan (Figure $2 c$ ), the interfaces between the electrolyte membrane and catalyst layers are less defined compared to the high resolution scan (Figure $2 \mathrm{~b}$ ) and in particular to the SEM image (Figure 2a). When performing manual measurements of the membrane thickness, the large field of view data is more prone to biasing by the subjectivity of the user. This is also reflected by a higher SD $(10 \mu \mathrm{m})$ compared to that from the high-resolution scan $(6 \mu \mathrm{m})$ and SEM $(5 \mu \mathrm{m})$, indicating that there is a higher degree of freedom in where to place the ends of the measurement lines in the large field of view X-ray CT image. Also, when the dataset contains information over a large field of view it is feasible to extract information over the entire area rather than just from the relatively few measuring points as is possible to obtain via manual measurements. In order to make a more complete and better estimation of the electrolyte membrane thickness over a large area of the MEA, despite the relatively lower data quality of the large field of view data, an algorithm for layer detection (described in Section 2.5) was used. 
Figure 4a-b shows the result of applying the algorithm to find surfaces of the electrolyte and catalyst layers. It should be emphasized that this surface detection is optimized by adjusting thresholds and fuzziness to give the most reliable results of the electrolyte membrane thickness. It was not an aim to optimize the surface detection to determine the thicknesses of the catalyst layers, although this method could have been optimized for these layers as well. Figure $4 \mathrm{~b}$ presents the results only for a close-up of a single 2D slice in the 3D dataset. Figure 4c presents a close-up of the detected surfaces in the full 3D for the dataset presented in Figure 4d. From the full dataset, the mean electrolyte membrane thickness of $44.6 \mu \mathrm{m}$ and SD $=14 \mu \mathrm{m}$ can be extracted. In the area from the close-up (Figure 4d) corresponding to Figure 2, the mean value is $41.2 \mu \mathrm{m}$ and SD $=11.6 \mu \mathrm{m}$. The values therefore agree well with the manual measurements. Figure $4 \mathrm{e}$ presents a thickness distribution, from which it can be seen that the measured thicknesses ranges from the lower limit of 1 pixel $(6.6 \mu \mathrm{m})$ to ca. 80 $\mu \mathrm{m}$. The periodically appearing peaks for every $6.6 \mu \mathrm{m}$ is an artefact related to the pixel resolution. Figure $4 \mathrm{f}$ is a thickness map from which is can be seen that the thickness is homogeneous over the 11 $\mathrm{mm} \times 11 \mathrm{~mm}$ field of view, except in a few areas (indicated with arrows) where the membrane appears to be thinner. Plane slices through a 3D dataset, like presented in Figure 3a, do not follow the bended layers and will not present the internal structures of the entire layer as it bends away from the plane. Contrary to this, once the layers have been detected, pixel intensities can be collected along the surface through the centre of the layers (Figure 4g). Such image describes the internal structure of the entire layer, as is shown in Figure $4 \mathrm{~h}-\mathrm{j}$ for the (h) top catalyst layer, (i) electrolyte membrane and (j) bottom catalyst layer. Comparing the electrolyte thickness map in Figure $4 \mathrm{f}$ (indicated by white arrows) to the images through the centre of the layers in Figure $4 \mathrm{~h}-\mathrm{j}$ shows that regions of apparently thin electrolyte are correlated regions in the catalyst layers with no or very little Pt. However, as mentioned earlier, the algorithm is dependent on the presence of Pt in catalyst layer for accurate measurement of electrolyte thickness. In regions with little Pt, there is almost no contrast between the electrolyte and the catalyst and for those region algorithm therefore fails to accurately determine the true thickness of the electrolyte. 


\subsection{Impact of the Sample Handling and Cell Testing on the Electrolyte Thickness}

Non-compressed materials were scanned by X-ray CT in order to determine the impact of the assembly procedure on the electrolyte membrane thickness. Despite clear delamination, resulting in the gap between the layers seen in Figure 5, the electrolyte membrane can be clearly identified as the central layer. Manual measurement of the non-compressed membrane showed that the mean thickness is 91 $\mu \mathrm{m}$ with $\mathrm{SD}=3 \mu \mathrm{m}$ and $\mathrm{SDOM}=1 \mu \mathrm{m}$.

An MEA from the same materials as the one presented in Figure 2 to Figure 5, was scanned in large field of view before cell test and immediately after. The scan was started within a few hours after the end of the test and the MEA was sealed in an aluminium enforced bag to shield it from ambient moisture during the transferral between electrochemical test equipment and X-ray $\mu \mathrm{CT}$ scanner.

Figure 6 presents results from the electrochemical cell test, specifically the voltage behaviour over a duration of $65 \mathrm{~h}$ including the respective conditions, exhibiting a steady improvement of the fuel cell performance. Besides the relatively long activation period of more than $65 \mathrm{~h}$, the MEA performance is representative and desirable.

The two 3D datasets recorded before and after cell test were analysed with the layer detection algorithm, and the results are presented in Figure 7a. The mean electrolyte membrane thickness measured before cell test is estimated to be $44 \pm 3 \mu \mathrm{m}$. After cell test the membrane thickness had decreased to $35 \pm 4 \mu \mathrm{m}$. The full list of measured thicknesses can be found in Table 1 .

Comparison of the thickness measurements show that a high decrease in membrane thickness of $52 \%$ occurs due to compression while a smaller decrease in thickness of $20 \%$ occurs during cell test. In total the electrolyte membrane thickness decreases by $62 \%$ from materials to tested MEA. For comparison, the thickness of a dry PBI membrane was measured to be $38-45 \mu \mathrm{m}$ using a micrometre with an accepted standard deviation of $\pm 10 \%$. Our measurements show that the thickness of a noncompressed doped membrane is approximately double of the dry thickness. The data obtained from 
the assembled MEA, however, indicates electrolyte thicknesses comparable with the dry membrane. It is noteworthy that the thickness increase, which is observed during doping and in the noncompressed sample does not seem to transfer to the assembled MEA. This allows the conclusion that a large fraction of the phosphoric acid migrates from the membrane to the electrode during the hotpressing step for MEA assembly.

From the layer detection, thickness distributions were extracted and are presented in Figure $7 \mathrm{~b}$ before and after cell test. Like the mean values, the distributions show that the membrane generally becomes thinner during cell test. The minimum membrane distance is in the layer detection algorithm set to 1 pixel $=6.6 \mu \mathrm{m}$, and this is the reason for the sharp cut-off in the distributions at this value.

In addition, Figure 7c- $d$ shows thickness maps and centre line images, also extracted from the layer detection. These show that the electrolyte membrane thickness is fairly homogenous across the MEA both before and after cell test. Weak vertical lines are observed in the thickness maps after, but not before cell test. This can also, and more clearly, be seen in the thickness map for the MEA depicted in Figure $4 \mathrm{f}$. The distance between these lines is ca. $2 \mathrm{~mm}$ corresponding to the distance between flow channels in the cell test setup. This suggests that the vertical lines is the imprint of the flow field pattern during cell assembly and electrochemical measurement. To the best knowledge of the authors, this is the first time plastic deformation of the electrolyte due to cell assembly in HT-PEMFCs is documented and is presumably also a result of the loss of phosphoric acid from the PBI polymer due to compression. This is in line with research done by Oono et al. [21,22], in which it is shown that the amount of phosphoric acid in the electrolyte membrane and electrode matrix is changing over the operational time of a HT-PEMFC and affects performance and mass flow properties.

\section{Conclusions}

Characterisation of membrane-electrode-assemblies (MEA) in high-temperature PEM fuel cells by SEM backscatter imaging was compared to imaging by X-ray $\mu \mathrm{CT}$. In particular, the electrolyte 
membrane morphology and thickness were analysed. The aim was to clarify whether sample handling during the respective analytical techniques influences the results.

The same mean electrolyte membrane thickness was found both with SEM and with X-ray $\mu \mathrm{CT}$.

Although the $\mathrm{X}$-ray $\mu \mathrm{CT}$ imaging offers a more realistic representation of the non-disturbed structures in the fuel cell, the results show that reliable membrane thickness measurements can also be achieved with SEM without any advanced sample preparation such as casting or ion-milling. The SEM results, however, showed delamination between layers in the MEA as a result of sample preparation.

The main advantage of $\mathrm{X}$-ray $\mu \mathrm{CT}$ for the present study is that it allows the same MEA to be studied before and after cell test. The results show that the mean electrolyte membrane thickness decreased by $52 \%$ due to compression of the materials during assembly and by almost $20 \%$ during fuel cell operation for $65 \mathrm{~h}$ at $160{ }^{\circ} \mathrm{C}$ and $0.4 \mathrm{~A} \mathrm{~cm}^{-2}$ with wet reformate on the anode. This shows that compression during MEA manufacturing is the dominant factor in the reduction of the membrane thickness from approximately $91 \mu \mathrm{m}$ down to the value close to that of the dry polymer. This indicates that the phosphoric acid is pressed from the membrane during compression, enters the GDE and presumably eventually leaves the cell with the gas stream. Thus, the assembly procedure itself is suspected to be driving the loss of phosphoric acid, which is one of the most severe factors limiting performance, catalyst utilisation and lifetime of HT-PEM fuel cells. This, however, requires further investigation.

\section{Acknowledgement}

The authors gratefully acknowledge funding received from the Danish Ministry of Energy, Utilities and Climate through the EUDP programme and Innovation Fund Denmark through the LINX project. The 3D Imaging Centre at The Technical University of Denmark is gratefully acknowledged.

\section{References}

[1] P. P. Edwards, V. L. Kuznetsov, W. I. F. David, N. P. Brandon, Energy Policy 2008, 36, 4356. 
[2] J. Wang, H. Wang, Y. Fan, Engineering 2018, 4, 352.

[3] Commercial HT-PEMFC products, can be found under https://serenergy.com, 2018.

[4] Commercial HT-PEMFC products, can be found under https://www.siqens.de, 2018.

[5] Q. Li, D. Aili, H. A. Hjuler, J. O. Jensen, High Temperature Polymer Electrolyte Membrane Fuel Cells, Springer International Publishing, Cham, 2016.

[6] J. Zhang, D. Aili, J. Bradley, H. Kuang, C. Pan, R. De Marco, Q. Li, S. P. Jiang, J. Electrochem. Soc. 2017, 164, F1615.

[7] J. Zhang, H. Zhang, J. Wu, J. Zhang in Pem Fuel Cell Test and Diagnosis, (Eds. J. Zhang, J. Wu H. Zhang, J. Zhang) Elsevier B.V., 2013, pp. 243.

[8] Q. Li, R. He, R. W. Berg, H. A. Hjuler, N. J. Bjerrum, Solid State lonics 2004, 168, 177.

[9] C. Korte, F. Conti, J. Wackerl, W. Lehnert in High Temp. Polym. Electrolyte Membr. Fuel Cells (Eds. Q. Li, D. Aili, H.A. Hjuler, J.O. Jensen), Springer International Publishing, Cham, 2016, pp. 169.

[10] R. T. White, A. Wu, M. Najm, F. P. Orfino, M. Dutta, E. Kjeang, J. Power Sources 2017, 350, 94.

[11] S. H. Eberhardt, F. Marone, M. Stampanoni, F. N. Büchi, T. J. Schmidt, J. Electrochem. Soc. 2016, 163, F842.

[12] M. Bodner, H. R. García, T. Steenberg, A. Vassiliev, S. M. Alfaro, G. S. Avcioglu, H. A. Hjuler, ECS Trans 2018, 86, 281.

[13] D. Aili, J. O. Jensen, Q. Li, in High Temp. Polym. Electrolyte Membr. Fuel Cells Approaches, Status, Perspect (Eds. D. Aili, Q. Li, H. A. Hjuler, J. O. Jensen), Springer, Switzerland, 2016 pp. 195.

[14] K. Li, X. Wu, D. Z. Chen, M. Sonka, IEEE Trans. Pattern Anal. Mach. Intell. 2006, 28, 119. 
[15] M. J. Emerson, K. M. Jespersen, A. B. Dahl, K. Conradsen, L. P. Mikkelsen, Appl. Sci. Manuf. $2017,97,83$.

[16] P. S. Jørgensen, K. V. Hansen, R. Larsen, J. R. Bowen, J. Microsc. 2011, 244, 45.

[17] P. S. Jørgensen, S. L. Ebbehøj, A. Hauch, J. Power Sources 2015, 279, 686.

[18] R. Scipioni, P. S. Jørgensen, D.-T. Ngo, S. B. Simonsen, Z. Liu, K. J. Yakal-Kremski, H. Wang, J. Hjelm, P. Norby, S. A. Barnett, S. H. Jensen, J. Power Sources 2016, 307, 259

[19] R. Scipioni, P. S. Jørgensen, D.-T. Ngo, S. B. Simonsen, J. Hjelm, P. Norby, S. H. Jensen, ECS Trans. 2015, 69, 71.

[20] R. Scipioni, P. S. Jørgensen, D. I. Stroe, R. Younesi, S. B. Simonsen, P. Norby, J. Hjelm, S. H. Jensen, Electrochim. Acta. 2018, 284, 454.

[21] Y. Oono, Ph.D. Thesis, Daido University, Minami-ku, Japan, 2013

[22] Y. Oono, A. Sounai, M. Hori, J. Power Sources 2009, 189, 943. 


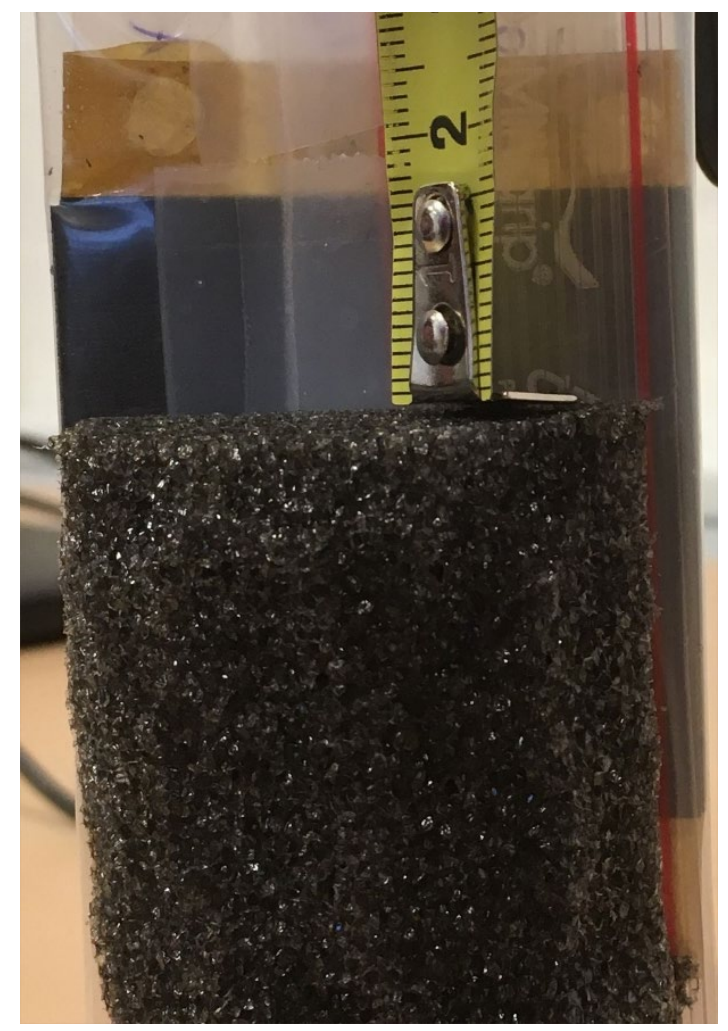

Figure 1: Photo of a MEA mounted for an X-ray $\mu$ CT scan in foam. Scale in centimetres.

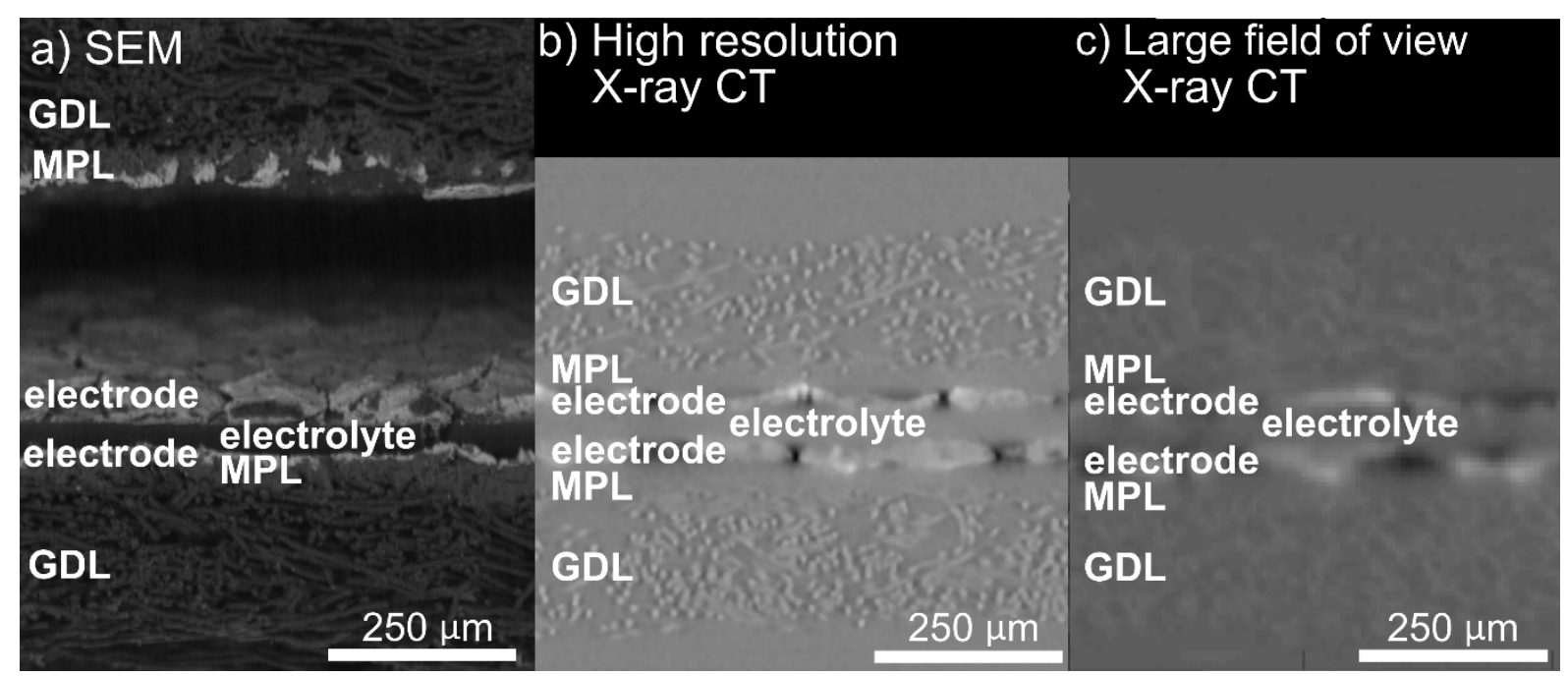

Figure 2: (a) Backscatter SEM image of an MEA after cell test. (b-c) X-ray CT image representing a single slice in the (b) high resolution 3D dataset (pixel size $=1.9 \mu \mathrm{m}$, area $=13 \mathrm{~mm}^{2}$ ) and $(\mathrm{c}$ ) the large field of view 3D dataset (pixel size $=6.6 \mu \mathrm{m}$, area $=121 \mathrm{~mm}^{2}$ ). $(\mathrm{b}, \mathrm{c}$ ) are from the same MEA as presented in (a). Cell layers including gas diffusion layers (GDL), micro porous layers (MPL), catalyst layers (CL) and the electrolyte membrane are indicated. 


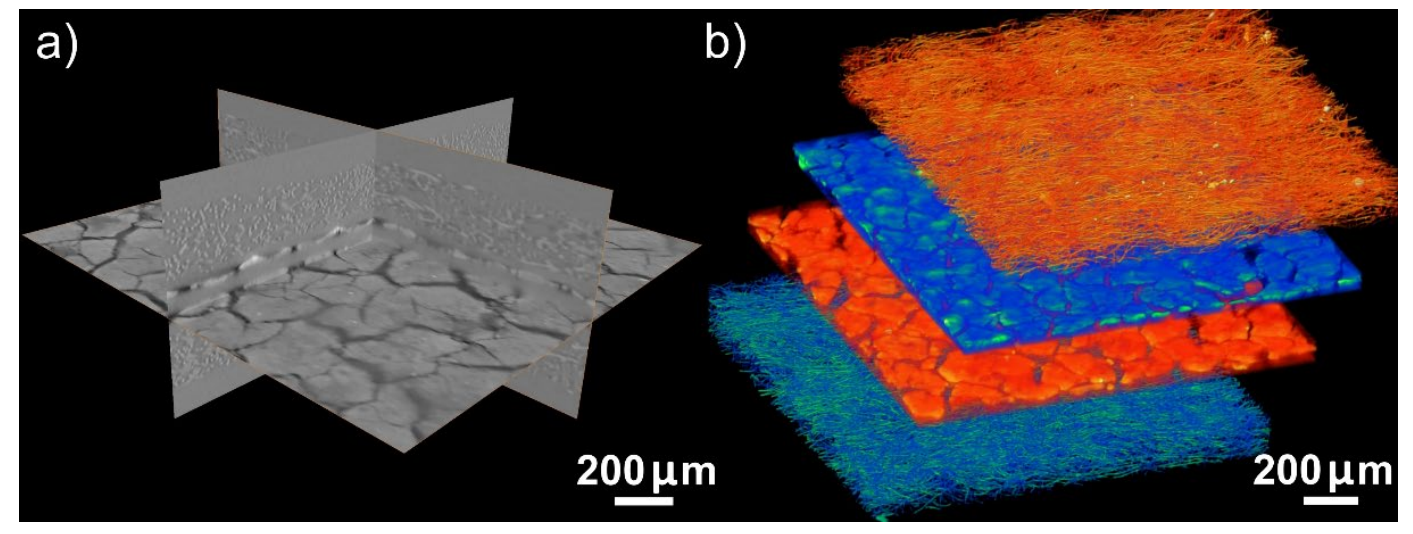

Figure 3: a) three orthogonal slices from the high-resolution 3D dataset obtained from X-ray $\mu C T$ scan of a tested MEA. b) Volume renderings of four selected layers in the MEA presented in different colour scales. From the top: GDL, catalyst layer, catalyst layer and GDL. The four layers are spatially shifted to make it easier to see the individual structures. 

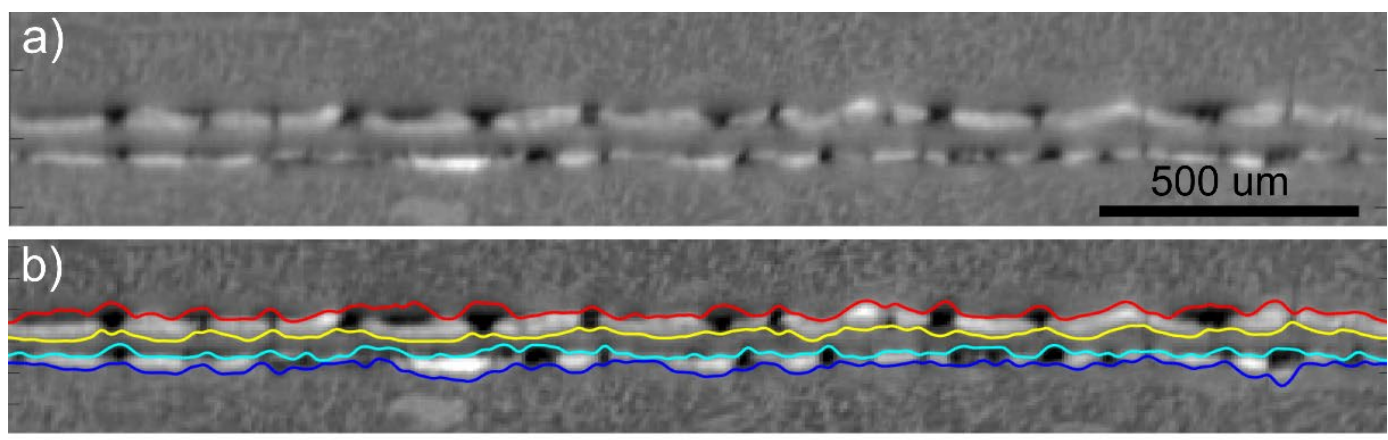

c)
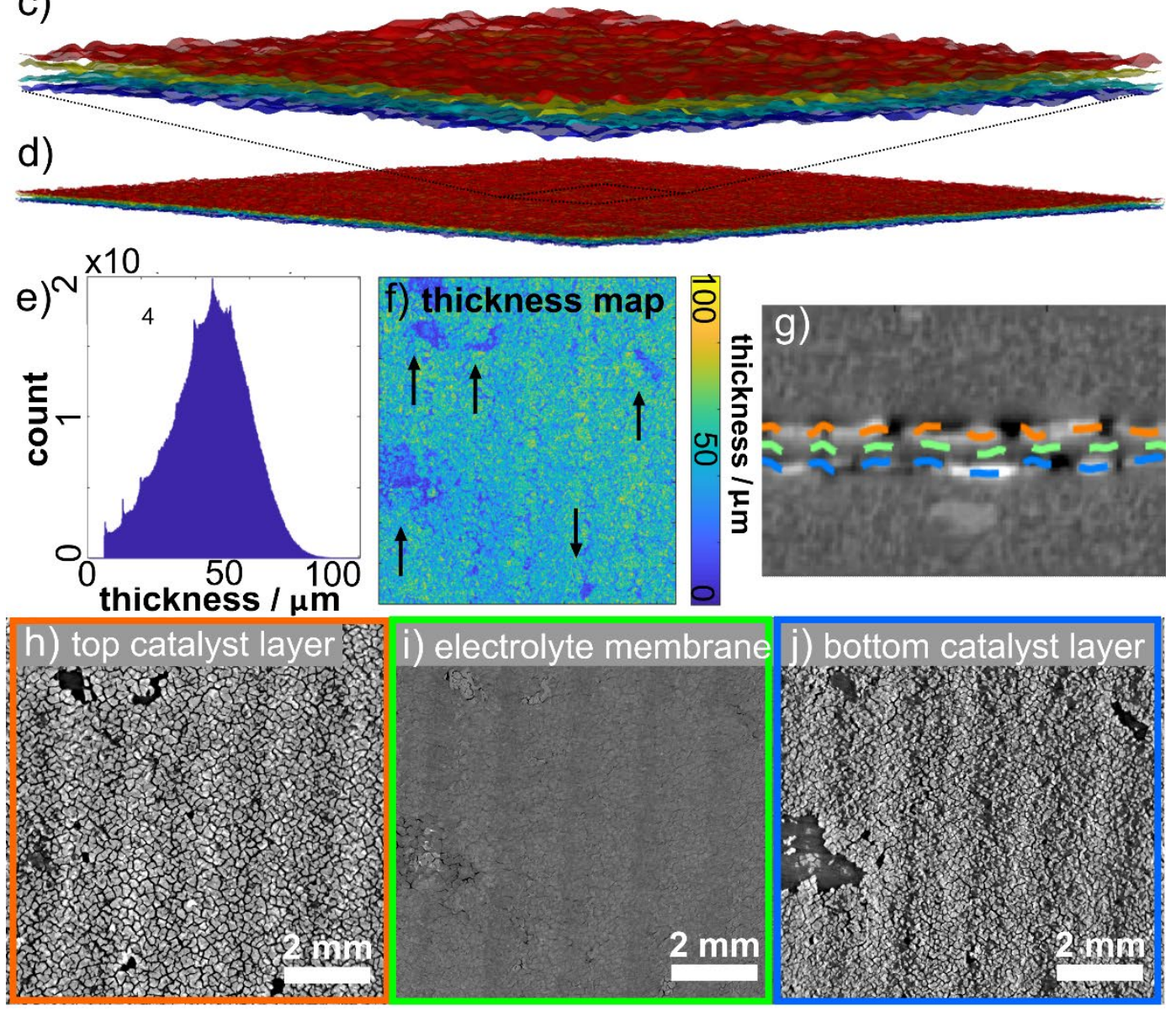

Figure 4: (a) X-ray CT image representing a single slice in the 3D dataset from the same MEA as presented in Figure 2. This image is a close-up from the large field of view scan. (b) Detected interfaces between the central layers of the MEA for the 2D slice presented in (a). (c) Close-up in 3D of the detected interfaces between the layers of the MEA presented in (d). (d) Detected interfaces between the central layers of the MEA for the entire dataset. (e) The distribution of the electrolyte thickness across the whole area of the MEA. (f) Thickness map of the electrolyte membrane. White arrows indicate regions identified as thin (g) Close-up of at slice in the dataset with lines through the centres of the three identified layers of the MEA. ( $h-j)$ Images presenting pixel values at the centre of the (h) top catalyst layer, (i) electrolyte membrane and (j) bottom catalyst layer. 


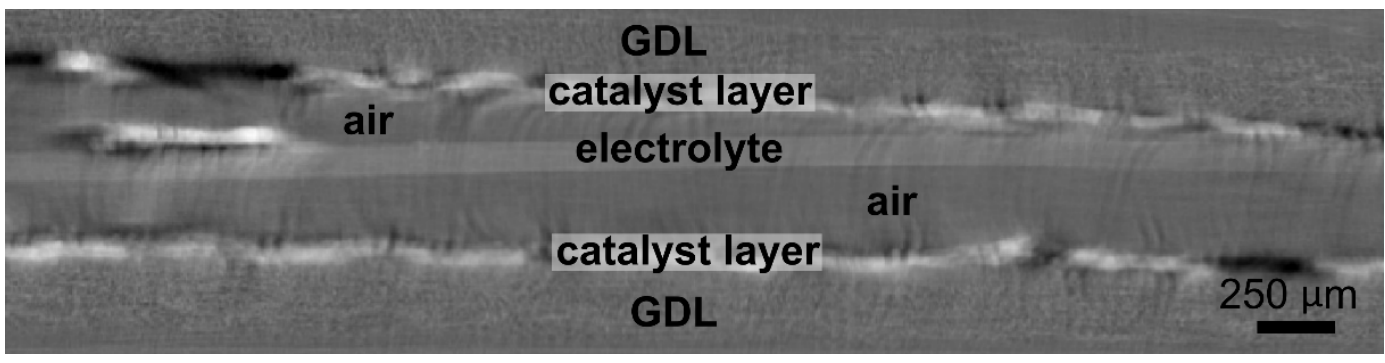

Figure 5: Close-up of an X-ray CT image representing a single slice in the 3D dataset from the high resolution X-ray CT scan of non-compressed MEA materials. The thin vertical lines are artefacts from the reconstruction.

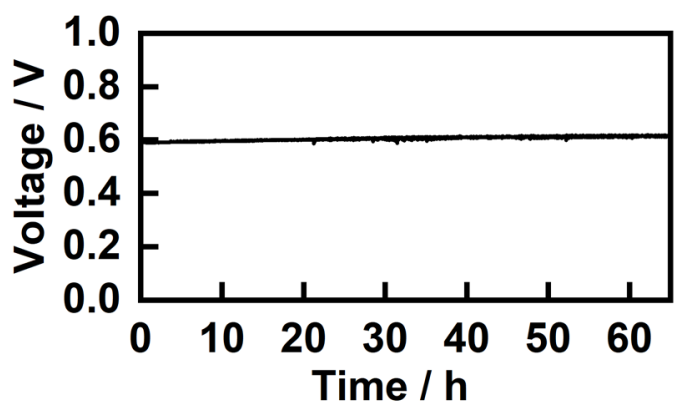

Figure 6: Steady-state electrochemical testing of an MEA with $21 \mathrm{~cm}^{2}$ active area over $65 \mathrm{~h}$ at $160{ }^{\circ} \mathrm{C}$ and $0.4 \mathrm{~A} \mathrm{~cm}^{-2}$ with wet reformate with a stoichiometry of $\lambda_{\mathrm{H} 2}=1.3$ on the anode and air with a stoichiometry of $\lambda_{\mathrm{O} 2}=2.5$ on the cathode. Reformate composition: $1.4 \% \mathrm{CO}, 22.3 \% \mathrm{CO}_{2}, 69.3 \% \mathrm{H}_{2}$, $6.9 \% \mathrm{H}_{2} \mathrm{O}$.

\section{a) segmentation}

before test
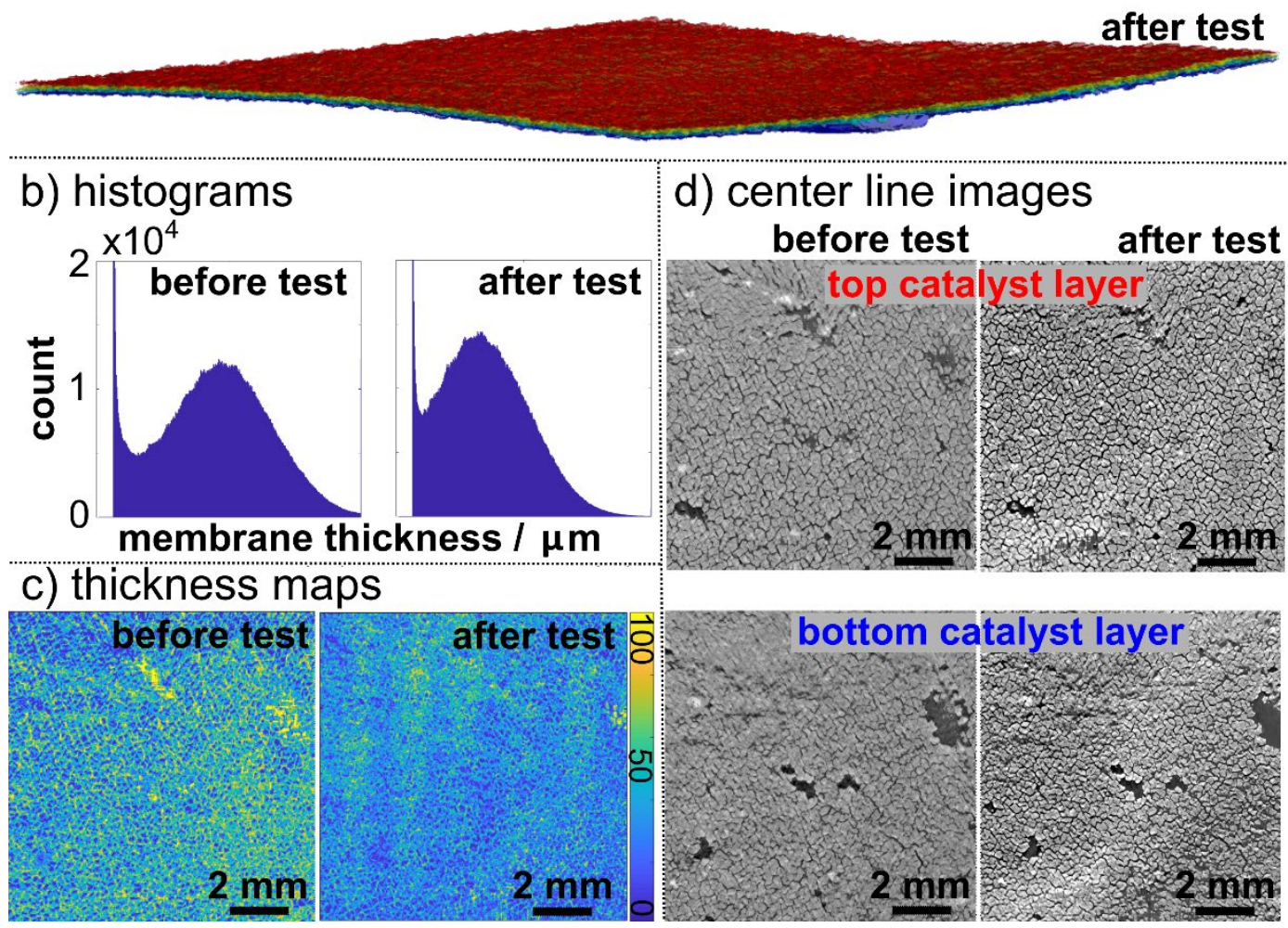
Figure 7: (a) 3D reconstruction of the identified interfaces between the central layers of the MEA from large field of view CT scan before and after cell test. (b) Histograms presenting the electrolyte membrane thickness before and after cell test. (c) Thickness maps of the electrolyte membrane before and after cell test. The colour scale indicates the thickness of only the electrolyte membrane in units of $\mu \mathrm{m}$. (d) Centre line images presenting pixel values at the centre lines before and after cell test at the top and bottom catalyst layer. 
Table 1: List of obtained polymer electrolyte membrane thicknesses for different materials and means of measurement.

\begin{tabular}{|c|c|c|c|c|c|}
\hline Material & Depicted in & Method & Evaluation method & $\begin{array}{c}\text { Thickness } \\
/ \mu \mathrm{m}\end{array}$ & $\begin{array}{c}\text { Measurement error } \\
\qquad / \mu \mathrm{m}\end{array}$ \\
\hline \multirow{3}{*}{ After cell test } & \multirow{3}{*}{ Figure 4} & $\begin{array}{l}\text { Large field of view } \\
\mu \mathrm{CT}\end{array}$ & \multirow{4}{*}{ Manual } & 42 & 2 \\
\hline & & High resolution $\mu \mathrm{CT}$ & & 41 & 1 \\
\hline & & SEM & & 43 & 1 \\
\hline Non-compressed & Figure 5 & High resolution $\mu \mathrm{CT}$ & & 91 & 1 \\
\hline After cell test & Figure 4 & \multirow{3}{*}{$\begin{array}{l}\text { Large field of view } \\
\qquad \mu \mathrm{CT}\end{array}$} & \multirow{3}{*}{ Algorithm } & 45 & 3 \\
\hline Before cell test & Figure 7 & & & 44 & 3 \\
\hline After cell test & Figure 7 & & & 35 & 4 \\
\hline
\end{tabular}

